\title{
EDITORIAL
}

\section{The Who's Who in Fluorescence 2009 Volume}

\author{
Chris D. Geddes
}

Published online: 15 May 2009

(C) Springer Science + Business Media, LLC 2009

In March 2009, The Who's Who in Fluorescence 2009, the 7th volume of the Who's who series was published.

This new 2009 volume features some 419 entries from no fewer than 41 countries worldwide, as compared to 418 entries (38 different countries) in 2008 and 405 entries in the 2007 volume, respectively. The volume received 29 new entries this year, and deleted 25 entries that were not updated by contributors from past years.

In 2008, 129 AIM numbers were submitted as compared to 106 in 2007. This year the number has risen again to 136 AIM numbers submitted. This year we also see the introduction of the $h$-index number listing, a publication statistic provided by the Thompson's ISI Web of Science. Some 42 contributors provided their $h$-numbers.
In 2009 we also see a continued and strong company support, in light of the current world economic climate, which will enable us to further disseminate the volume in 2009-2010. In this regard we especially thank the instrumentation companies for their continued support, where without their financial contributions, it is likely that the volume would not be the success it is today.

Finally, a special thank you goes to Caroleann Aitken, the Who's Who in Fluorescence Coordinator for both the architecture and the typesetting of the entire volume in a timely fashion.

Thank you all,

Kind Regards

Dr Chris D. Geddes, Professor

April 28th 2009.

C. D. Geddes $(\bowtie)$

The Institute of Fluorescence,

Baltimore, MD, USA

e-mail: geddes@umbi.umd.edu 